\title{
Demographic predictors of active tuberculosis in people migrating to British Columbia, Canada: a retrospective cohort study
}

\author{
Lisa A. Ronald PhD, Jonathon R. Campbell PhD, Robert F. Balshaw PhD, Kamila Romanowski MSc, \\ David Z. Roth MSc, Fawziah Marra PhD, Victoria J. Cook MD, James C. Johnston MD
}

Cite as: CMAJ 2018 February 26;190:E209-16. doi: 10.1503/cmaj.170817

Visual abstract available at www.cmaj.ca/lookup/suppl/doi:10.1503/cmaj.170817/-/DC2

\begin{abstract}
BACKGROUND: Canadian tuberculosis (TB) guidelines recommend targeting postlanding screening for and treatment of latent tuberculosis infection (LTBI) in people migrating to Canada who are at increased risk for TB reactivation. Our objectives were to calculate robust longitudinal estimates of TB incidence in a cohort of people migrating to British Columbia, Canada, over a 29-year period, and to identify groups at highest risk of developing TB based on demographic characteristics at time of landing.
\end{abstract}

METHODS: We included all individuals ( $n=1080908)$ who became permanent residents of Canada between Jan. 1 ,
1985, and Dec. 31, 2012, and were resident in BC at any time between 1985 and 2013. Multiple administrative databases were linked to the provincial TB registry. We used recursive partitioning models to identify populations with high TB yield.

RESULTS: Active TB was diagnosed in 2814 individuals (incidence rate 24.2/ 100000 person-years). Demographic factors (live-in caregiver, family, refugee immigration classes; higher TB incidence in country of birth; and older age) were strong predictors of TB incidence in $\mathrm{BC}$, with elevated rates continuing many years after entry into the cohort.
Recursive partitioning identified refugees 18-64 years of age from countries with a TB incidence greater than $224 / 100000$ population as a high-yield group, with $1 \%$ developing TB within the first 10 years.

INTERPRETATION: These findings support recommendations in Canadian guidelines to target postlanding screening for and treatment of LTBI in adult refugees from high-incidence countries. Because high-yield populations can be identified at entry via demographic data, screening at this point may be practical and high-impact, particularly if the LTBI care cascade can be optimized.
A $s$ tuberculosis (TB) transmission declines in regions of low TB incidence, TB is becoming concentrated in migrant populations. ${ }^{1}$ In Canada, a country with low TB incidence, most cases of TB (about 70\%) are diagnosed in people born outside of Canada, with many arriving from countries with a high TB incidence. ${ }^{2}$

Preimmigration medical screening is a cornerstone of TB prevention in Canada. Prospective permanent residents and temporary residents who will be staying in Canada for more than 6 months undergo a preimmigration medical examination that includes a history, physical examination and chest radiograph, and when indicated by radiograph abnormalities, sputum samples for smear and culture. Applicants with a diagnosis of active TB must receive treatment before they can obtain residency status. ${ }^{2}$ Postimmigration surveillance of select individuals is also conducted, whereby people considered to be at high risk for TB (i.e., evidence of prior TB or abnormalities present on chest radiographs) are highlighted for follow-up surveillance by public health authorities in Canada. ${ }^{2} \mathrm{How}$ ever, a recent study found that less than $3 \%$ of active cases of TB in people migrating to Canada were detected by postimmigration surveillance. ${ }^{3}$ Currently, no routine pre- or postimmigration screening and treatment programs for latent TB infection (LTBI) for people migrating to Canada are available. ${ }^{2}$

Scale-up of LTBI screening and treatment in high-risk populations postimmigration is a component strategy for achieving World Health Organization (WHO) targets for TB elimination in Canada. ${ }^{4,5}$ However, with about 250000 new permanent residents migrating to Canada annually, the large population of people who may qualify for LTBI screening and treatment is a substantial barrier to implementation. ${ }^{6}$ National guidelines recommend targeting screening for LTBI in people migrating from high-incidence countries, particularly in adult refugees up to 50 years of age and those with other risk factors for increased TB reactivation. ${ }^{2,4}$ However, many of these recommendations are based on weak evidence. ${ }^{2} \mathrm{~A}$ 
better understanding of who is at highest risk for active TB after immigration to Canada is needed.

Our objectives were to calculate robust longitudinal estimates of TB incidence in people migrating to British Columbia, Canada, over a 29-year period, and to identify groups at highest risk of TB based on demographic characteristics at the time of immigration.

\section{Methods}

\section{Study population and data sources}

This study is part of a larger project to describe risk factors for TB among people migrating to BC. The study setting, cohort, databases and linkage methods have been described previously. ${ }^{7}$ Briefly, we derived our data from a permanent linkage between the Permanent Resident database (Immigration, Refugees and Citizenship (anada) and Population Data BC, a multiuniversity resource with a large collection of health services data. ${ }^{8}$ For this analysis, we extracted data on demographics from the Permanent Resident database and the provincial Medical Services Plan (MSP), MSP registration dates, deaths from Vital Statistics records and TB testing from the provincial TB registry. ${ }^{9-15}$ Data were linked using unique scrambled identification numbers. ${ }^{16}$ Use of similar methods to link the Immigration, Refugees and Citizenship Canada database with Ontario health administrative databases has been found to have high linkage accuracy. ${ }^{17}$

We included all permanent residents landing in Canada between Jan. 1, 1985, and Dec. 31, 2012, and establishing residency in BC at any point between Jan. 1, 1985, and Dec. 31, 2013, in the cohort. We defined landing as the first date when an individual entered Canada with their permanent resident visa. Individuals were identified as resident in BC when they registered for MSP, the universal health insurance program administered by the government of BC. Enrolment in MSP is mandatory for all eligible $B C$ residents and their dependents, and has a monthly fee; therefore, we considered MSP coverage a good proxy measure for residence in BC.

We started calculation of follow-up time at each individual's index date, which we defined as 90 days before the date of MSP registration. We censored follow-up at the earliest of first active TB diagnosis, end of MSP coverage, time of death or end of study (Dec. 31, 2013). Diagnosis of TB was based on data from the TB registry, and included all TB sites that were confirmed microbiologically or clinically.

\section{Demographic risk factors}

We included the following variables: age at index date, year of index date, gender, country of birth, incidence of TB in the country of birth and immigration class. We derived incidence rates of TB in the country of birth from annual country-level WHO data for incidence of TB (all forms of TB/100000 population). ${ }^{18}$ We further grouped incidence based on Canadian TB standards cut-points, where countries with a high TB incidence are classified as those with an incidence greater than $30 / 100000$ population. ${ }^{19}$ We categorized immigration classes based on categories from Immigration, Refugees and Citizenship Canada: ${ }^{20}$ family, refugee, other, and 3 types of economic immigration classes (business, skilled workers and live-in caregivers). Live-in caregivers are a specific skilled-worker stream that has been reported to have significantly higher TB incidence in Canada compared with other immigration classes. ${ }^{3}$ All economic class applicants are able to sponsor themselves and their dependents within these immigration streams.

\section{Statistical analysis}

As a primary outcome, we calculated active TB incidence as the number of TB cases per 100000 person-years at risk, with 95\% confidence intervals $(\mathrm{Cls})$ based on a Poisson distribution. We accounted for lapses in MSP registration by excluding lapsed periods from the person-years denominator.

We stratified outcomes by demographic characteristics and by elapsed time since index date. To describe the relation between TB incidence rates as a smooth function of the number of years since index date, we used a generalized additive model with a cubic regression spline for time. Because of variability in rates of TB incidence when denominators for person-years were small, we limited plots of rates of TB incidence to the first 20 years after the index date.

We also used recursive partitioning to help identify population groups with high TB incidence in the first 10 years after landing. Recursive partitioning is a data-driven method for multivariable analysis that can handle complex interactions among predictor variables, and predictor variables that may have a nonlinear association with the outcome. ${ }^{21,22}$ For predictors, we included demographic variables identifiable at the time of immigration: age, gender, immigration class and incidence of TB in the country of birth. We focused our primary analysis on 10-year outcomes (because most cases of TB occurred within the first 10 years) that were limited to participants less than 65 years of age (because treatment for LTBI is not likely to be offered to people $65 \mathrm{yr}$ of age or older) and who had an index year before 2004 (to allow for $10 \mathrm{yr}$ of follow-up for each person). We visualized the results by plotting the 10-year Kaplan-Meier survival curves that were evaluated for each identified population group (i.e., the terminal nodes of the tree). As a sensitivity analysis, we ran a logistic regression model using categories and interactions identified by recursive partitioning, with little substantive change in results.

All analyses were conducted in $\mathrm{R}$ (version 3.2.5; The R Project for Statistical Computing), with $95 \% \mathrm{Cls}$ that were calculated using the epitools package (version 0.5-7). Graphs were produced using the R ggplot2 (version 2.1.0) and survminer packages (version 0.2.4). Classification trees were constructed using the rpart (version 4.1-10) and rpart.plot (version 1.5.3) packages.

\section{Ethics approval}

This study received ethical approval from the Clinical Research Ethics Board of the University of British Columbia (H16-00265).

\section{Results}

\section{Cohort characteristics}

We included 1080908 individuals in the cohort (Table 1). Participants were followed for a median of 10 years (interquartile range 
[IQR] 5-17 yr), with a total follow-up of 11.6 million person-years (Appendix 1, supplemental Figure 1, available at www.cmaj.ca/ lookup/suppl/doi:10.1503/cmaj.170817/-/DC1).
The median age of the cohort population was 30 years (IQR 19-41 yr) at index date. Almost half of the individuals migrated through the skilled worker stream (41\%); refugees accounted for

Table 1: Characteristics of people in the study cohort at index date, and incidence rates of tuberculosis during study follow-up

\begin{tabular}{|c|c|c|c|c|}
\hline Characteristic & $\begin{array}{l}\text { No. of people in the } \\
\text { cohort (\%) } \\
n=1080908\end{array}$ & $\begin{array}{c}\text { No. of person-years } \\
(1000 \mathrm{~s}) \\
n=11640\end{array}$ & $\begin{array}{c}\text { No. of cases of TB } \\
\text { in } \text { BC }^{*} \\
n=2814\end{array}$ & $\begin{array}{l}\text { No. of cases of TB/ } \\
100000 \text { person-year } \\
(95 \% \mathrm{Cl})\end{array}$ \\
\hline All & & & & $24.2(23.3-25.1)$ \\
\hline \multicolumn{5}{|l|}{ Age group, yr } \\
\hline $0-4$ & $45998(4.3)$ & 520 & 22 & $4.2(2.7-6.4)$ \\
\hline $5-14$ & $152560(14.1)$ & 1756 & 129 & $7.3(6.1-8.7)$ \\
\hline $15-34$ & $453538(42.0)$ & 4858 & 1132 & $23.3(22.0-24.7)$ \\
\hline $35-54$ & $327781(30.3)$ & 3434 & 743 & $21.6(20.1-23.2)$ \\
\hline $55-64$ & $59256(5.5)$ & 669 & 419 & $62.6(56.8-68.9)$ \\
\hline$\geq 65$ & 41775 (3.9) & 403 & 369 & $91.6(82.5-101.4)$ \\
\hline \multicolumn{5}{|l|}{ Sex } \\
\hline Female & $553976(51.3)$ & 6071 & 1391 & $22.9(21.7-24.1)$ \\
\hline Male & $526932(48.8)$ & 5569 & 1423 & $25.6(24.2-26.9)$ \\
\hline \multicolumn{5}{|l|}{ Immigration class } \\
\hline Business $†$ & $168357(15.6)$ & 1915 & 240 & $12.5(11.0-14.2)$ \\
\hline Skilled worker† & $440778(40.8)$ & 4295 & 573 & $13.3(12.3-14.5)$ \\
\hline Live-in caregiver $\dagger$ & $28640(2.7)$ & 278 & 129 & $46.4(38.7-55.1)$ \\
\hline Refugee & $86803(8.0)$ & 1069 & 362 & $33.9(30.5-37.5)$ \\
\hline Family & $326106(30.2)$ & 3723 & 1387 & $37.3(35.3-39.3)$ \\
\hline Other§ & $30224(2.8)$ & 359 & 123 & $34.3(28.5-40.9)$ \\
\hline \multicolumn{5}{|l|}{ WHO Region of birthฯ } \\
\hline Southeast Asia & $153061(14.2)$ & 1631 & 698 & $42.8(39.7-46.1)$ \\
\hline Africa & 31161 (2.9) & 320 & 101 & $31.6(25.7-38.4)$ \\
\hline Western Pacific & $586669(54.3)$ & 6476 & 1773 & $27.4(26.1-28.7)$ \\
\hline Eastern Mediterranean & $84057(7.8)$ & 778 & 134 & $17.2(14.4-20.4)$ \\
\hline The Americas & $80297(7.4)$ & 839 & 49 & $5.8(4.3-7.7)$ \\
\hline Europe & $145661(13.5)$ & 1595 & 59 & $3.7(2.8-4.8)$ \\
\hline \multicolumn{5}{|l|}{ TB rate in country of birth ${ }^{\star \star}$} \\
\hline $0-30$ cases $/ 100000$ population & $186165(17.2)$ & 1733 & 37 & $2.1(1.5-2.9)$ \\
\hline $31-100$ cases/100 000 population & $278081(25.7)$ & 2582 & 249 & $9.6(8.5-10.9)$ \\
\hline $101-200$ cases/100 000 population & $340901(31.5)$ & 4067 & 952 & $23.4(21.9-24.9)$ \\
\hline$>200$ cases $/ 100000$ population & $275759(25.5)$ & 3257 & 1576 & $48.4(46.0-50.8)$ \\
\hline \multicolumn{5}{|l|}{ Index year } \\
\hline 1985-1994 & $299501(27.7)$ & 5051 & 1386 & $27.4(26.0-28.9)$ \\
\hline 1995-2004 & $443941(41.1)$ & 5032 & 1084 & $21.5(20.3-22.9)$ \\
\hline $2005-2013$ & $337466(31.2)$ & 1556 & 344 & $22.1(19.8-24.6)$ \\
\hline
\end{tabular}

Note: $\mathrm{BC}=$ British Columbia, $\mathrm{Cl}=$ confidence interval, $\mathrm{TB}=$ tuberculosis. Missing data: country of birth $(n=2)$.

*Includes respiratory (70\%) and nonrespiratory (30\%) TB sites.

†Economic immigration classes include both principal applicants and their dependents.

IIncludes government-assisted (46\%), privately sponsored (26\%), asylum (22\%) and dependents abroad (6\%).

§Includes retirees (57\%), deferred removal orders and postdetermination refugee claimants in Canada (7\%), permit holders applying for permanent residence ( $3 \%)$, and humanitarian and compassionate cases (36\%).

ฯCountries/territories in each WHO Health Region (based on most person-time spent in BC): Southeast Asia (India, Sri Lanka, Indonesia), Africa (South Africa, Kenya, Ethiopia), Western

Pacific (China, Hong Kong, Philippines), Eastern Mediterranean (Iran, Pakistan, Afghanistan), Americas (United States, El Salvador, Mexico), Europe (United Kingdom and colonies,

Poland, Germany) (Appendix 1, supplemental Table 1 [available at www.cmaj.ca/lookup/suppl/doi:10.1503/cmaj.170817/-/DC1] provides a more extensive list).

${ }^{*}$ Values are World Health Organization estimates for an individual's year of index = number of TB cases (all forms)/100 000 population. 
$8 \%$ of the cohort population. Over half of the cohort population was born in the Western Pacific Region; 3 major source areas were China (including Taiwan, Hong Kong and Macao [34\%]), India (12\%) and Philippines (9\%). Most people (83\%) originated from high TBincidence countries (i.e., incidence $>30 / 100000$ population, with $26 \%$ originating from countries with incidence $>200 / 100000$ population [Table 1]). The proportion of individuals migrating from countries with a TB incidence greater than 30/100 000 population peaked in 1994 (Figure 1). The proportion of skilled workers increased (22.4\% during index years $1985-1994$ v. 46.7\% during index years 2005-2013) and the proportion of refugees decreased ( $11.7 \%$ v. $5.5 \%$ ) across the 29 -year study period (data not shown).

\section{Tuberculosis outcomes}

Active TB was diagnosed in 2814 people, for an incidence rate of $24.2 / 100000$ person-years over the study period (Table 1 ). Most cases $(71 \%)$ were diagnosed in the first 10 years after the index date; rates of TB incidence declined sharply over the first 5 years and remained relatively stable after 10 years (Figure $2 A$ ).

Incidence of TB increased with older age at index date (Table 1 ), with the highest rates in individuals 65 years of age or older (91.6/100000 person-years, 95\% Cl 82.5-101.4). Tuberculosis incidence was highest among the following classes: live-in caregiver (46.4/100 000 person-years, 95\% Cl 38.7-55.1), family (37.3/100 000 person-years, $95 \% \mathrm{Cl} 35.3-39.3)$ and refugee
(33.9/100 000 person-years, 95\% Cl 30.5-37.5). Tuberculosis incidence rates increased in a dose-response manner with increasing TB incidence in the country of birth, whereby rates among individuals with a birth-country TB incidence of more than 200/100000 population (48.4/100000 person-years, 95\% Cl 46.050.8 ) were more than 21 times higher than those born in a country with a TB incidence of 0-30/100000 population, (2.1/100000 personyears, $95 \% \mathrm{Cl}$ 1.5-2.9). These patterns were observed over elapsed time since index date (Figure 2B, Figure 2C and Figure 2D) and across immigration time periods (data not shown).

Our analyses using recursive partitioning suggested 21 groups at risk of TB based on demographic characteristics (Appendix 1, supplementary Table 2). Kaplan-Meier curves for 10-year survival (Figure 3) for these groups showed that adult refugees who migrated from countries with a TB incidence of more than $224 / 100000$ population were among the most likely to be diagnosed with active TB, with about $1 \%$ developing TB within 10 years after the index date. At a TB incidence threshold of more than $224 / 100000$ population, about $0.7 \%$ of people aged 18-64 years in the family, live-in caregiver and other immigration classes developed TB within 10 years (Figure 3). Among individuals migrating within any immigration class from countries with a TB incidence of $132 / 100000$ population or less (Appendix 1, supplemental Table 2$)$, the yield of TB cases was low $(<0.1 \%$ of 423193 individuals $(n=396)$ developed TB within $10 \mathrm{yr})$.

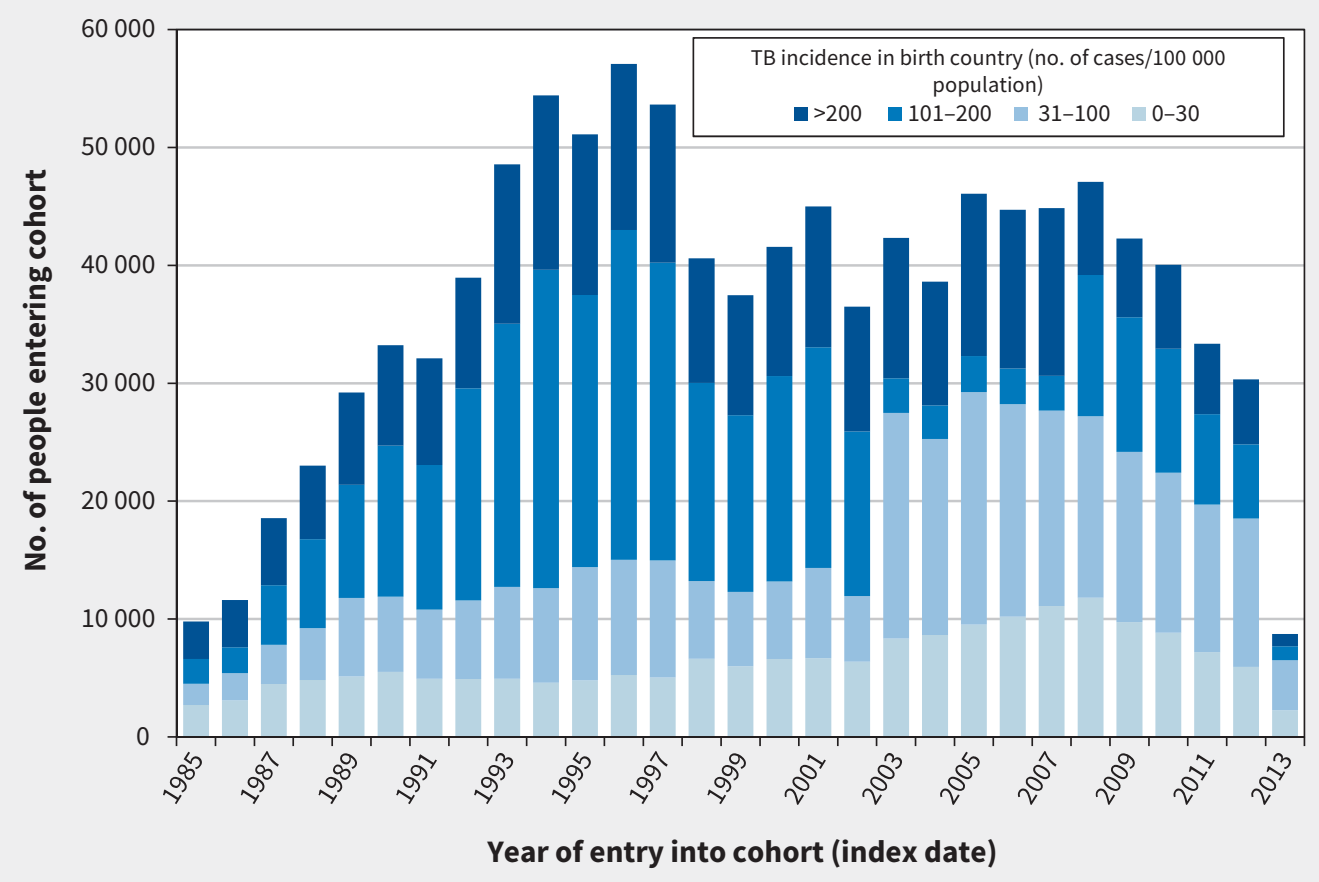

Figure 1: Number of people entering the study cohort each year from 1985 to 2013, stratified by the WHO-estimated TB incidence in the country of birth $(n=1080$ 908). Note: TB = tuberculosis, WHO = World Health Organization. 


\section{Interpretation}

Our cohort represents a near-complete capture of data for demographic characteristics, immigration and health service utilization for more than a million people migrating to $\mathrm{BC}$ over a 29-year period. Our study adds to the understanding of longterm TB incidence in migrant populations in Canada by showing that rates remain elevated up to 2 decades after migration. Demographic factors (i.e., live-in caregiver, family and refugee immigration classes; higher TB incidence in country of birth; and older age) were strong predictors of TB incidence in $\mathrm{BC}$, with the differential rates observed across demographic factors continuing for many years after arrival. Refugees aged 18-64 years from countries with a TB incidence of more than 224/100000 population had the highest TB yield.

Our findings parallel studies estimating person-years in calculations of TB rates. ${ }^{23-26}$ For example, in a large study in the United States the rates remained elevated up to 19 years after arrival. ${ }^{24}$

\section{A) All people}

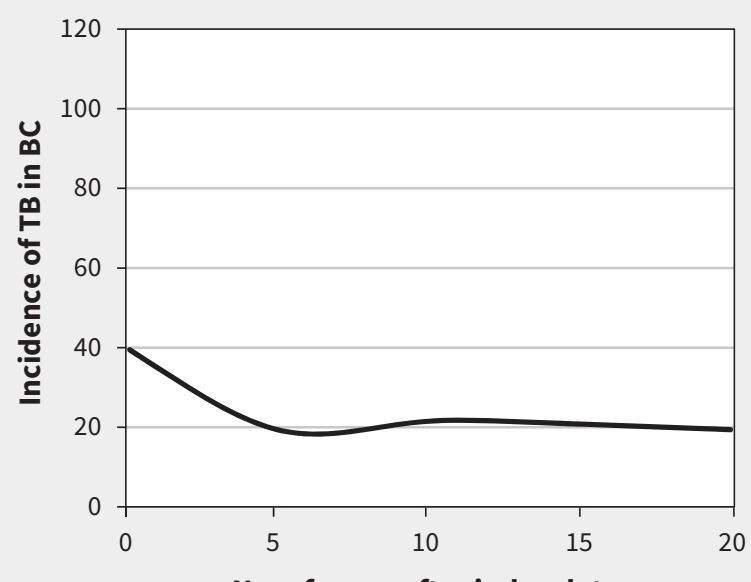

No. of years after index date

\section{C) Immigration class}

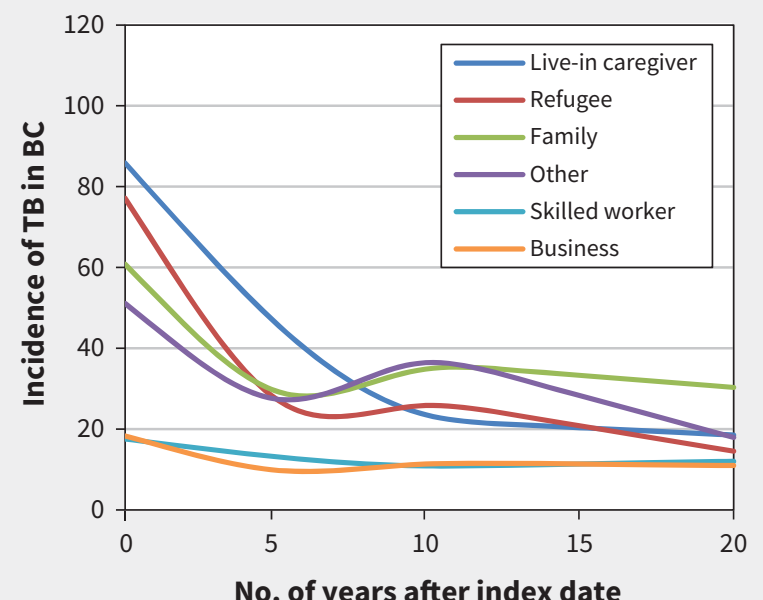

No. of years after index date

\section{D) Incidence of TB in birth country}

(No. cases/100 000 population)

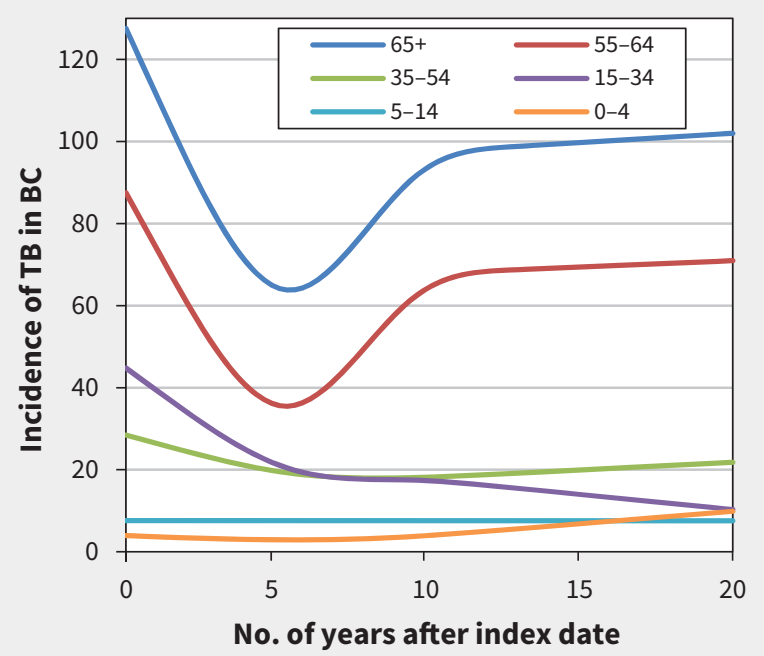

\section{B) Age group at index date (in years)}

Figure 2: Incidence of TB among migrants in BC (no. of cases/100000 person-years at risk), stratified by the number of years since index date and demographic characteristics. (A) All participants, (B) age group, (C) immigration class and (D) incidence of TB in the country of birth. Rates of TB incidence (no. of TB cases $/ 100000$ person-years) modelled as a smooth function of the number of years since index date using generalized additive models, with time represented as a cubic regression spline (degrees of freedom $=4$ ) with knots set to the 30th, 50th, 70th and 90th percentiles of time (in accumulated person-years). Note: $\mathrm{BC}=$ British Columbia, $\mathrm{TB}=$ tuberculosis.

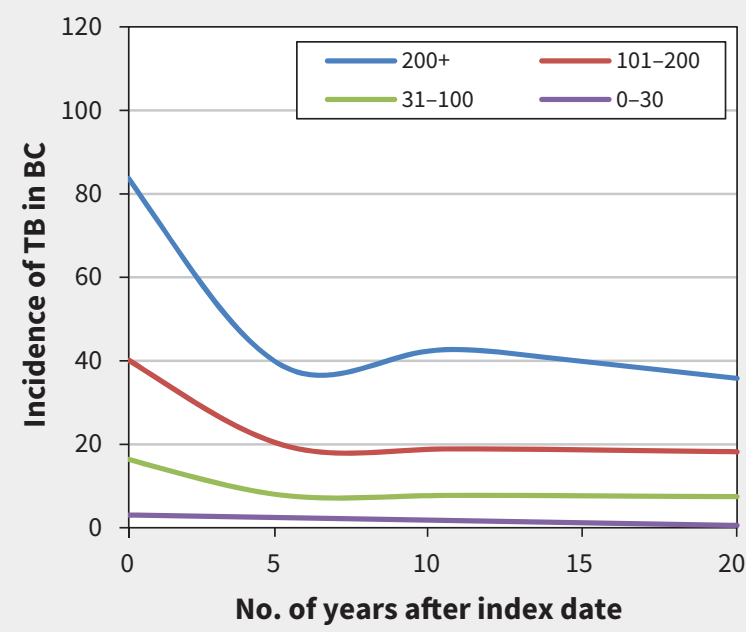




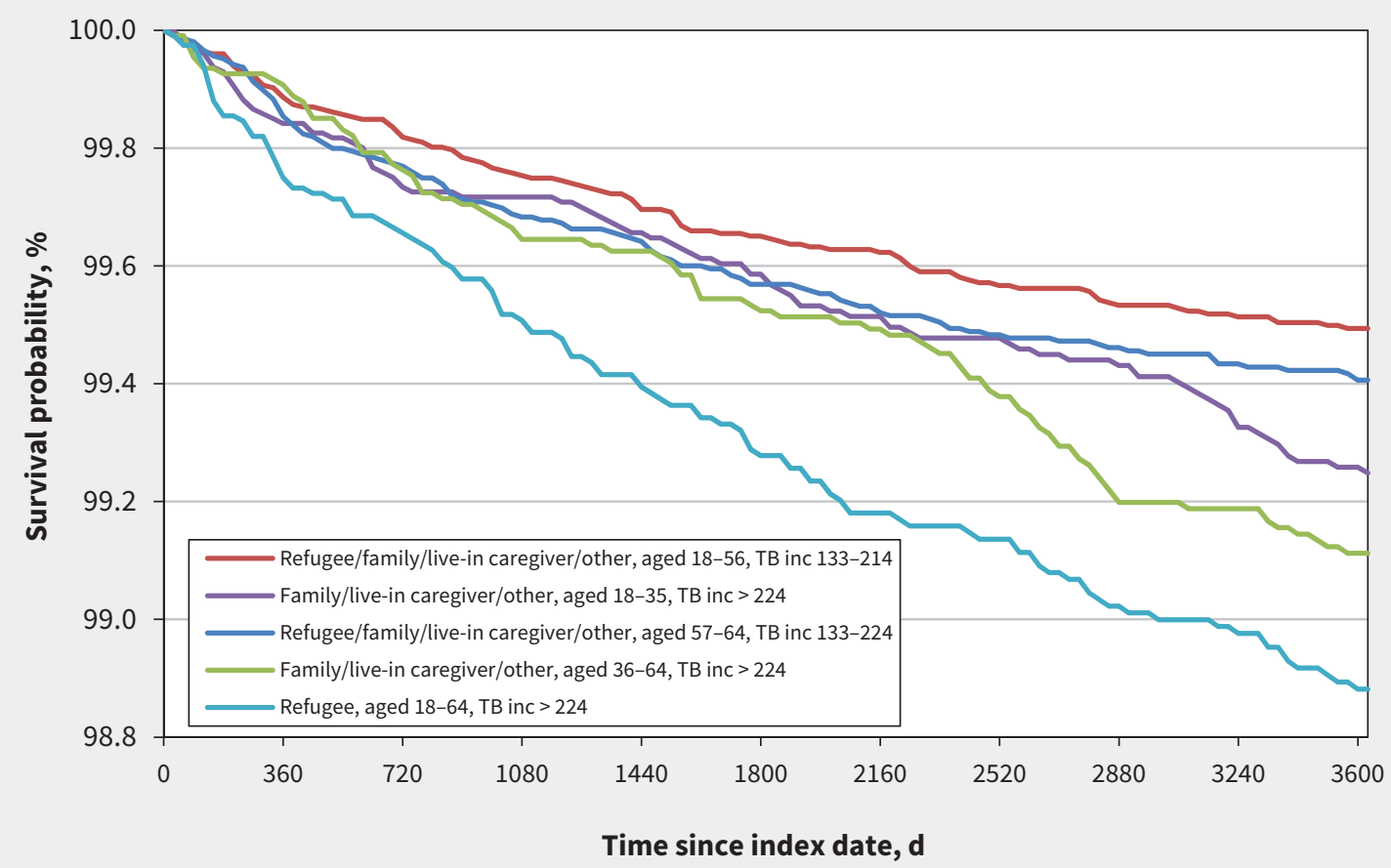

Figure 3: Kaplan-Meier curves of 10-year TB outcomes within population subgroups identified by recursive partitioning models (plot shows the groups with highest TB yield). Analysis included participants with index years from 1985 to 2003 and aged less than 65 years at index date $(n=676294)$. Note: inc $=$ World Health Organization estimate for TB incidence in country of birth in index year (no. of TB cases [all forms] $/ 100000$ population), TB = tuberculosis.

Our finding that refugee and live-in caregiver classes had some of the highest $\mathrm{TB}$ rates among people migrating to $\mathrm{BC}$ complements previous Canadian findings. ${ }^{3}$ Our study further adds to this recent cohort study reporting 2-year TB incidence among people migrating to Ontario ${ }^{3}$ by including a longer follow-up time to assess TB incidence rates across years since immigration, by using MSP records to estimate time spent in province, by including a more detailed breakdown of immigration classes and by using recursive partitioning methods to determine the groups at highest risk of TB after immigration.

\section{Limitations}

The Immigration, Refugees and Citizenship Canada database includes only individuals who have received permanent landing status. Therefore, this study necessarily excluded temporary visitors and workers, some refugee applicants and undocumented migrants. Although temporary migrants account for a large proportion of people entering Canada, ${ }^{2}$ it is unlikely that the epidemiologic patterns we observed would differ markedly between temporary versus permanent migrant populations. Second, it is possible that lapsed MSP coverage may not be a good proxy for leaving the province, and thus we may have estimated time spent in BC incorrectly. However, we found that TB rates were markedly lower during break periods for MSP coverage compared with nonbreak periods, which supports our assumption that participants were not in BC during these periods. In addition, we could not identify travel to a high-incidence country or family clusters; if new infections were acquired after immigration, the public health impact of LTBI screening at time of immigration may be overestimated. As well, the small number of deaths not related to TB (compared with TB cases diagnosed pre- or postmortem) suggests the potential for bias due to competing risks is negligible. Finally, as is typical with health administrative database studies, misclassification because of inaccurate health administrative data is possible.

\section{Implications and knowledge gaps}

Identifying higher-risk groups based on demographic factors at time of immigration is a first step toward improving LTBI screening and treatment programs for people migrating to Canada. Our results support recommendations to target postlanding $\mathrm{LTBI}$ screening and treatment to adult refugees originating from countries with a high TB incidence. ${ }^{2,4,27}$ Although the public health impact may not be high given the relatively small population, LTBI screening of adult refugees from countries with a high TB incidence should be a feasible first step to implement (e.g., in $B C$, this represents up to an estimated 600 people annually). Many WHO European-region countries screen for both TB and LTBI in refugee centres. ${ }^{28}$ In Canada, refugees who are assisted by the government are placed in a reception house until 
permanent housing can be located; during this period, refugees receive a medical evaluation, which could provide an opportunity for LTBI screening. ${ }^{29}$ High rates of LTBI screening and treatment completion have also been reported in a Canadian refugee clinic. ${ }^{29}$ Notably, Canadian guidelines for TB recommend LTBI screening for refugees up to age 50 years and to age 65 years when sufficient monitoring for drug-related adverse events can be ensured. ${ }^{4}$

We did not investigate adverse events related to LTBI treatment; however, based on TB rates, our results support screening some groups up to the age of 65 years. As well, given the generally low rates of TB among people migrating from countries with a TB incidence below 132/100000 population, this suggests a higher threshold for targeting LTBI screening and treatment programs in Canada, in particular when other medical risk factors are not present.

Provision of screening and treatment for LTBI among people who are migrating as domestic caregivers from countries with a high TB incidence may also be suggested, given consistent findings of higher TB rates after migration to Canada. Live-in caregivers to Canada migrate predominantly from settings with a high TB incidence ${ }^{30}$ and often work in health care-related professions before immigration, ${ }^{31}$ where TB exposure may be higher than in the general population. ${ }^{32}$

To achieve WHO elimination targets for Canada, other high-risk groups also need to be identified. Evaluation of TB risk associated with immune-suppressive comorbidities in this cohort is an important next research step. Evaluation of the cost-effectiveness of different LTBI programs is also needed. Although a number of studies from low-incidence countries suggest that LTBI screening in migrants from high-incidence countries is cost-effective, ${ }^{5,33-35}$ there remains uncertainty about optimal thresholds for screening. ${ }^{36}$ In addition, more research is needed to optimize the LTBI care cascade, because the impact of screening will be limited if treatment completion is poor. ${ }^{37}$ For example, a recent systematic review suggested that fewer than one-fifth of people successfully completed LTBI screening and treatment programs. ${ }^{38}$ Finally, more research is needed to understand TB-related outcomes and barriers to accessing health care among vulnerable migrant populations. ${ }^{39,40}$

\section{Conclusion}

With high-yield populations easily identified via demographic data, LTBI screening and treatment at entry may be practical and potentially high-impact, particularly if the LTBI care cascade can be optimized. Using demographic data alone, we found that adult refugees from countries with a high TB incidence had the highest rates of TB incidence within the first 10 years of cohort entry. Screening this vulnerable group may be a practical first step toward more comprehensive LTBI screening in migrant populations arriving in Canada.

\section{References}

1. Lönnroth K, Migliori GB, Abubakar I, et al. Towards tuberculosis elimination: an action framework for low-incidence countries. Eur Respir J 2015;45:928-52.

2. Canadian tuberculosis standards, 7 th ed. Ottawa: Canadian Thoracic Society and Public Health Agency of Canada; 2014:1-469. Available: www.popdata.bc.ca/ (accessed 2017 Mar. 30).
3. Khan K, Hirji MM, Miniota J, et al. Domestic impact of tuberculosis screening among new immigrants to Ontario, Canada. CMAJ 2015;187:E473-81.

4. Greenaway C, Sandoe A, Vissandjee B, et al. Tuberculosis: evidence review for newly arriving immigrants and refugees. CMAJ 2011;183:E939-51.

5. Pareek M, Greenaway C, Noori T, et al. The impact of migration on tuberculosis epidemiology and control in high-income countries: a review. BMC Med 2016; 14:48.

6. Campbell J, Marra F, Cook V, et al. Screening immigrants for latent tuberculosis: Do we have the resources? CMAJ 2014;186:246-7.

7. Ronald LA, Campbell JR, Balshaw RF, et al. Predicting tuberculosis risk in the foreign-born population of British Columbia, Canada: study protocol for a retrospective population-based cohort study. BMJ Open 2016;6:e013488.

8. Population Data BC. Available: www.popdata.bc.ca/ (accessed 2017 May 12).

9. Immigration, Refugees and Citizenship Canada [creator] (2014): Population Data BC [publisher]. Data Extract. CIC (2015). Available: www.popdata.bc.ca/ data (accessed 2018 Jan. 31).

10. BC Vital Statistics Agency [creator] (2015): Vital Statistics Deaths. V2. Population Data BC [publisher]. Data Extract. BC Vital Statistics Agency (2014). Available: www.popdata.bc.ca/data (accessed 2018 Jan. 31).

11. British Columbia Ministry of Health [creator] (2015): Consolidation File (MSP Registration \& Premium Billing). Population Data BC [publisher]. Data Extract. MOH (2014). Available: www.popdata.bc.ca/data (accessed 2018 Jan. 31).

12. British Columbia Ministry of Health [creator] (2015): Medical Services Plan (MSP) Payment Information File. Population Data BC [publisher]. Data Extract. MOH (2014). Available: www.popdata.bc.ca/data (accessed 2018 Jan. 31).

13. Canadian Institute for Health Information [creator] (2015): Discharge Abstract Database (Hospital Separations). Population Data BC [publisher]. Data Extract. MOH (2014). Available: www.popdata.bc.ca/data (accessed 2018 Jan. 31).

14. BC Ministry of Health [creator] (2015): PharmaNet. BC Ministry of Health [publisher]. Data Extract. Data Stewardship Committee (2014). Available: www. popdata.bc.ca/data (accessed 2018 Jan. 31).

15. BC Centre for Disease Control [creator] (2015): BC Provincial TB Registry (BCCDC-iPHIS). Population Data BC [publisher]. Data Extract. BCCDC (2014). Available: www.popdata.bc.ca/data (accessed 2018 Jan. 31).

16. Population Data BC. Data linkage. Available: www.popdata.bc.ca/datalinkage (accessed 2017 Sept. 5).

17. Chiu M, Lebenbaum M, Lam K, et al. Describing the linkages of the immigration, refugees and citizenship Canada permanent resident data and vital statistics death registry to Ontario's administrative health database. BMC Med Inform Decis Mak 2016;16:135.

18. WHO World TB Database. Available: www.who.int/tb/country/data/download/ en/ (accessed 2016 Apr. 22).

19. Greenaway C, Khan K, Schwartzman K. Tuberculosis surveillance and screening in selected high-risk populations. In: Canadian tuberculosis standards, 7th ed. Ottawa: Public Health Agency of Canada; 2014:1-469. Available: www.respiratoryguidelines. ca/sites/all/files/Canadian_TB_Standards_7th_Edition_ENG.pdf. (accessed 2017 Jan. 18).

20. Glossary of terms and concepts. In: Facts and figures 2014 - immigration overview: permanent residents. Ottawa: Citizenship and Immigration Canada; 2014. Available: www.cic.gc.ca/english/resources/statistics/facts2014/glossary.asp (accessed 2017 Mar. 26).

21. Therneau T, Atkinson E; Mayo Foundation. An introduction to recursive partitioning using the RPART routines. 2018. Available: https://cran.r-project.org/ web/packages/rpart/vignettes/longintro.pdf (accessed 2017 Jan. 7).

22. Strobl C, Malley J, Tutz G. An introduction to recursive partitioning: rationale, application, and characteristics of classification and regression trees, bagging, and random forests. Psychol Methods 2009;14:323-48.

23. Lillebaek T, Andersen AB, Dirksen A, et al. Persistent high incidence of tuberculosis in immigrants in a low-incidence country. Emerg Infect Dis 2002;8:679-84.

24. Zuber PL, McKenna MT, Binkin NJ, et al. Long-term risk of tuberculosis among foreign-born persons in the United States. JAMA 1997;278:304-7.

25. Walter ND, Painter J, Parker M, et al. Persistent latent tuberculosis reactivation risk in United States immigrants. Am J Respir Crit Care Med 2014;189:88-95.

26. Cain KP, Benoit SR, Winston CA, et al. Tuberculosis among foreign-born persons in the United States. JAMA 2008;300:405-12.

27. de Vries G, van Rest J, Meijer W, et al. Low yield of screening asylum seekers from countries with a tuberculosis incidence of $<50$ per 100000 population. Eur Respir J 2016;47:1870-2.

28. D'Ambrosio L, Centis R, Dara M, et al. European policies in the management of tuberculosis among migrants. Int J Infect Dis 2017;56:85-89. 
29. Rennert-May E, Hansen E, Zadeh T, et al. A step toward tuberculosis elimination in a low-incidence country: successful diagnosis and treatment of latent tuberculosis infection in a refugee clinic. Can Respir J 2016;2016:7980869.

30. Kelly P, Park S, de Leon C, et al. Profile of live-in caregiver immigrants to Canada, 1993-2009. Toronto: Toronto Immigrant Employment Data Initiative, York University; 2011:1-18. Available: www.yorku.ca/tiedi/doc/AnalyticalReport18. pdf (accessed 2017 Mar. 28).

31. Salami B, Nelson S, Hawthorne L, et al. Motivations of nurses who migrate to Canada as domestic workers. Int Nurs Rev 2014;61:479-86.

32. Menzies D, Joshi R, Pai M. Risk of tuberculosis infection and disease associated with work in health care settings. Int J Tuberc Lung Dis 2007;11:593-605.

33. Oxlade $\mathrm{O}$, Schwartzman K, Menzies D. Interferon-gamma release assays and TB screening in high-income countries: a cost-effectiveness analysis. Int J Tuberc Lung Dis 2007;11:16-26.

34. Pareek M, Watson JP, Ormerod LP, et al. Screening of immigrants in the UK for imported latent tuberculosis: a multicentre cohort study and cost-effectiveness analysis. Lancet Infect Dis 2011;11:435-44.
35. Zammarchi L, Casadei G, Strohmeyer M, et al. A scoping review of cost-effectiveness of screening and treatment for latent tubercolosis infection in migrants from highincidence countries. BMC Health Serv Res 2015;15:412.

36. Pareek M, Baussano I, Abubakar I, et al. Evaluation of immigrant tuberculosis screening in industrialized countries. Emerg Infect Dis 2012;18:1422-9.

37. Cain KP, Garman KN, Laserson KF, et al. Moving toward tuberculosis elimination: implementation of statewide targeted tuberculin testing in Tennessee. Am J Respir Crit Care Med 2012;186:273-9.

38. Alsdurf $\mathrm{H}$, Hill PC, Matteelli A, et al. The cascade of care in diagnosis and treatment of latent tuberculosis infection: a systematic review and meta-analysis. Lancet Infect Dis 2016;16:1269-78.

39. Zelnick JR, O'Donnell MR, Ahuja SD, et al. Health care provider perspectives on tuberculosis care for foreign-born populations in New York City. Int J Tuberc Lung Dis 2016;20:1625-32.

40. Abarca Tomas B, Pell C, Bueno Cavanillas A, et al. Tuberculosis in migrant populations: a systematic review of the qualitative literature. PloS One 2013;8:e82440.

\section{Competing interests: None declared.}

This article has been peer reviewed.

Affiliations: Division of Respiratory Medicine, Faculty of Medicine (Ronald, Cook, Johnston), University of British Columbia; BC Centre for Disease Control (Ronald, Balshaw, Romanowski, Roth, Cook, Johnston); Faculty of Pharmaceutical Sciences (Campbell, Marra), University of British Columbia, Vancouver, BC

Contributors: James Johnston and Lisa Ronald are the primary study investigators. James Johnston initiated the project and led the design of the grant. All of the authors are investigators on the project, and contributed to the study design and analysis; reviewed the manuscript critically for important intellectual content; gave final approval of the version to be published; and agreed to be accountable for all aspects of the work.

Funding: This work is funded through grants provided by the Michael Smith Foundation for Health Research, the BC Lung Association and the Canadian Institutes of Health Research.

Disclaimer: All inferences, opinions and conclusions drawn in this manuscript are those of the authors, and do not reflect the opinions or policies of the data steward(s).

Acknowledgements: The authors would like to acknowledge the people who were part of this cohort. The authors have attempted to use nonstigmatizing language but acknowledge that their terminology may be imperfect. The authors thank Leslie Chiang and Fay Hutton for assistance with data cleaning, and Dr. Maureen Mayhew for her feedback on methods. This work is led by the BC Centre for Disease Control and the University of British Columbia. The partners in research are Population Data BC; Immigration, Refugees and Citizenship Canada; BC Ministry of Health; BC Cancer Agency; and BC Renal Agency.

Accepted: Oct. 12, 2017

Correspondence to: James Johnston, James. Johnston@bccdc.ca 